Rev. Latinoam. Psicopat. Fund., São Paulo, 20(2), 382-398, jun. 2017

http://dx.doi.org/10.1590/1415-4714.2017v20n2p382.11

\title{
El joven Joyce y el pathos del lenguaje
}

Julieta De Battista*1

Este artículo ofrece una construcción del caso Joyce como un relato clínico a partir de los lineamientos que Lacan subrayó en 1975-1976. Metodológicamente se basa en la obra autobiográfica sobre la infancia $y$ adolescencia de James Joyce y ofrece una lectura de la constelación original del nacimiento, la posición fundacional de la orientación subjetiva, los efectos del rechazo y el pathos singular que lo aquejaba: las palabras impuestas o experiencia del lenguaje parásito.

Palabras clave: Psicoanálisis, psicosis, literatura, síntoma

*1 Comisión de Investigaciones Científicas de la provincia de Buenos Aires (La Plata, Argentina). 
LITERATURA, PSICOPATOLOGIA

\section{Introducción}

Este artículo tiene como objetivo ofrecer una primera construcción del caso Joyce bajo la forma de un relato clínico, a partir de los lineamientos que Lacan (1975-1976/2005a) señaló relativos al pathos que lo afectaba con respecto al lenguaje. Retomaremos las indicaciones que se consideran heurísticas para aportar el material de la obra autobiográfica joyciana en la que podrían fundamentarse, haciendo especial hincapié en algunas experiencias de la infancia y la adolescencia relatadas en Stephen Hero y Portrait of the artist as a young man.

La propuesta de Lacan es considerar esta parte de la obra de este literato de genio como un testimonio de sus síntomas, "Lo que escribe es consecuencia de lo que es" (Lacan, 19751976/2005a, p. 79). Lacan sostiene que Stephen Dedalus, protagonista de ambas obras, es James Joyce (p. 69). Esta aseveración no resulta infundada, dado que los biógrafos de Joyce (Ellman, S. Joyce, Gorman) coinciden en afirmar el carácter netamente autobiográfico de estos dos libros, al reconocer que los mismos se basan sobre experiencias vividas por Joyce (Gorman, 1941/1945, p. 81; Ellmann, 1959/1991, p. 27; Spencer, 1960, p. 15). Además Stephen Dedalus fue el seudónimo con el que Joyce comenzó a intentar ser publicado, por lo tanto no podría reducírselo meramente a un personaje literario (Joyce, S., 1960, p. 267).

Por otra parte, es conocida la crítica de Joyce a la novela psicológica ficcionada y romántica propia de la época y su estilo calificado como un realismo psicológico que pretende captar a los hombres tal y como son en su experiencia viva 


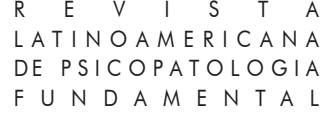

(Joyce, S. 1960, p. 42, 87). Para Joyce, la revelación de la intimidad del alma era la misión más grande del poeta y luchaba para que no se falseara su experiencia espiritual con la psicología literaria de la ficción de aquella época, a la que acusaba de crear en los hombres una falsa e hipócrita conciencia literaria de héroes legitimados (Joyce, S., 1960, p. 206). Era entonces un realista despiadado de la literatura que elegía como fundamento de su obra las vidas comunes, la verdad desnuda (p. 118-120).

Por lo tanto, el tipo de escritura innovadora y característica de Joyce vuelve a este material sumamente valioso para el propósito de reconstruir el caso, dado que ambos libros despliegan con alto grado de detalle la particular experiencia que Joyce tenía de la realidad, su erlebnis vital, su singular manera de "habitar" el lenguaje. Algunos críticos han descripto a esta modalidad de escritura innovadora como una stream of consciousness, un monólogo interior que intenta reproducir la experiencia tal y como es, sin embellecerla a través de la ficción.

El uso de la obra literaria como aporte a las investigaciones en psicoanálisis se inscribe en la perspectiva inaugurada por Freud (1907/1999a, 1910/1999b) y continuada por Lacan (1966a, 2001a) de servirse del artista 384 en la indagación de la condición humana. Artista y psicoanalista trabajan con el sufrimiento de los hombres, intentan elaborar idéntico objeto con distinto método, de ahí que el testimonio de los primeros es de sumo valor para el psicoanalista y las coincidencias que el analista pueda encontrar en su lectura de la obra toca las constelaciones reales (Freud, 1907/1999a). El artista precede al analista en su materia, le abre el camino (Lacan, 1965/2001a), si el analista puede no hacerse el "psicólogo" de la obra sino seguirla al pie de la letra para reconocer cómo la práctica de la letra converge con el uso del inconsciente y permite deslindar el orden riguroso de la composición del sujeto (Lacan, 1965/1966a, p. 745).

En sentido estricto no se trata de un ejercicio de psicoanálisis aplicado, dado que en este caso no se aplica el psicoanálisis como tratamiento, pero sí de una investigación en psicoanálisis puesto que la operación de lectura que se utiliza para conformar el caso clínico releva del método analítico: toma el material como un síntoma y lee lo que el mismo presenta de significante, dejando en suspenso los efectos de significación presupuestos. Desde esta

${ }^{1}$ Véase el artículo de Sonia Leite (2016) donde trabaja la relación habitar-construir y el valor del cuerpo propio. 


\section{LITERATURA, PSICOPATOLOGIA}

perspectiva la obra de juventud de los artistas cobra especial relevancia, dada la significatividad que el psicoanálisis otorga a las experiencias infantiles (Freud, 1906-1908/1979). La aplicación de este método ha brindado valiosos aportes a la teoría que fueron deslindados del análisis de la obra y/o la biografía de Jensen (Freud, 1907/1999a), Leonardo da Vinci (Freud, 1910/1999b), Dotoievsky (Freud, 1928/1994), Gide (Lacan, 1958/1966a; Miller, 1990), Marguerite Duras (Lacan, 1965/2001a), Rousseau, Pessoa, Joyce (Soler, 2001), Althusser (Pommier, 1998), entre otros. El uso de la obra literaria no se reduce a la mera ilustración y/o confirmación de la teoría, sino que revela la potencia heurística de las hipótesis psicoanalíticas en la lectura del sufrimiento que es inherente al ser humano.

Consideramos que este trabajo de construcción del caso a partir de material autobiográfico y biográfico aporta datos de relevancia en la comprensión del pathos que aquejaba a Joyce con respecto al lenguaje y que permite iluminar el carácter de su solución sinthomática. Cabe destacar que las investigaciones en psicoanálisis que se han ocupado de Joyce han privilegiado este último aspecto, ligado a la escritura en el final de su obra (Finnegan's wake), en tanto aporta líneas de investigación sobre la relación del sujeto con lalengua y sobre las modalidades de compensación nodal que no se referencian en la versión común de la metáfora paterna (Julien, 2001; Miller, 2007; Soler, 2001). De esta manera, en la literatura analítica contemporánea, el caso Joyce se ha vuelto paradigmático de las llamadas "psicosis no desencadenadas" (Kong, 2011) o incluso de las psicosis ordinarias, en las que se resalta el papel del cuerpo a nivel de los fenómenos (Redmond, 2014; Rosa, 2009; Svolos, 2009), cuestión que se abordará en otro trabajo para abocarse en éste a las manifestaciones del pathos del lenguaje.

\section{Método de construcción del caso}

El método de construcción del relato del caso produce en el material una operación de lectura sobre los siguientes puntos:

- Constelación original a la que el sujeto advino: inscripción en las generaciones y la filiación, condiciones del deseo de la madre y del padre.

- Posición fundacional de la orientación subjetiva ante las condiciones dadas del nacimiento: aceptación de la referencia paterna o rechazo y sus efectos a nivel de la experiencia del lenguaje. 


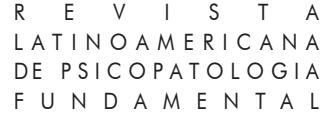

- Delimitación del pathos singular que acompaña a la posición subjetiva en la estructura del lenguaje, coyunturas y modalidades de soportarlo: alcances y limitaciones.

El armado del caso procede entonces por inferencias retrospectivas a partir de los sucesos y de las experiencias que Joyce ubica como claves en su vida. El corpus de material a indagar con esta orientación está constituido por las obras de Joyce que tratan sobre sus años de niñez y adolescencia (Stephen Hero, Portrait of the artist as a young man) y las biografías de Ellman, Gorman y su propio hermano, Stanislaus Joyce. Hemos privilegiado en la argumentación aquellos datos que son destacados en forma convergente por todos los biógrafos y que revelan el relato de una experiencia.

\section{Constelación original: "pauvre hère"}

La constelación del nacimiento de Joyce está marcada por condiciones adversas a nivel del deseo. Lacan lo deja señalado al advertir: "No se podría haber empezado peor que él” (Lacan, 1975-1976/2005a, p. 15). James Joyce es el segundo hijo del matrimonio entre John Stanislaus Joyce y Mary ("May") Jane Murray, calificado por los vecinos como una unión entre bella y bestia: "Si él era el principio del caos, ella era el principio del orden" (Ellmann, 1959/1991, p. 34); "(Mary) Era una sombra opaca al lado de la figura refulgente de su esposo (...) ella sólo aparece como un fantasma, una imagen encantadora, piadosa, que iba siendo arrastrada lentamente hacia la inanición. (...) Creía humildemente en todo aquello de que su marido se burlaba descaradamente" (Gorman, 1945, p. 16-17). Ninguna de las dos familias estuvo de acuerdo con este casamiento. La madre de John nunca lo perdonó y murió al poco tiempo. El rasgo de unión entre los padres fue la música, ambos cantaban en un coro. May tuvo una educación musical y John estaba orgulloso de su voz de tenor, de ahí que la especialidad de la casa fuera la música vocal (Ellmann, 1959/1991, p. 34-35, 41; Gorman, 1945, p. 15-16), cada uno de los niños tenía su canción (Joyce, S., 1960, p. 39).

Por lo demás, este matrimonio transcurría en la continua degradación que hacía el padre de la familia materna, al enaltecer únicamente la ascendencia del apellido Joyce y vanagloriarse de descender del clan de los Galway. El padre de Joyce se quejaba de que el apellido materno "le arrojaba un hedor insoportable a las narices" (Ellmann, 1959/1991, p. 27) y repetía, según testimonio de las hermanas de Joyce, “iMira con qué me he casado!” (p. 35, 839 n. 36). Conservaba un escudo de armas de los Galway-Joyce que "(...) llevó consigo 


\section{LITERATURA, PSICOPATOLOGIA}

magnífica y quijotescamente, en medio de sus frecuentes mudanzas forzadas, compensando así la dilapidación de la fortuna familiar con la conservación del blasón putativo" (Ellmann, 1959/1991, p. 27; Joyce, S., 1960, p. 147).

El apellido Joyce deriva del francés joyeux (Gorman, 1945, p. 12). Pero no era precisamente un clima de alegría el que se respiraba en la casa. El padre de Joyce era ya un gran bebedor, un gentleman con trabajos inestables y que vivía de las rentas que le había dejado la herencia de su padre. Era un "monumento de indolencia" (Gorman, 1945, p. 14). Perseguía obsesivamente a la familia de la madre, llegando incluso a mudarse para que ellos no pudieran visitarla (Joyce, S., 1960, p. 55). Los celos injustificados del padre convivían con los retratos de sus ex novias sobre la mesa familiar (Joyce, S., 1960, p. 63). John Joyce siempre fue un bon vivant que captaba agudamente los detalles del vecindario, una suerte de enciclopedia viviente de curiosidades locales y anécdotas, una "fuente inagotable de la chismografía de Dublín" (Joyce, S., 1960, p. 89; Ellmann, 1959/1991, p. 30). Fracasó en lo académico al estudiar medicina, pero era un excelente cantante y actor, excesivamente cómico, aunque no lograra tampoco vivir de eso (Ellmann, 1959/1991, p. 31, 36; Gorman, 1945, p. 13). Según el hermano de Joyce, el padre siempre estaba buscando trabajo, "pero uno adecuado para un hombre que no quiere trabajar" (Joyce, S., 1960, p. 88). La relación con la madre de Joyce comenzó a complicarse con la llegada de los hijos y alcanzó situaciones de extrema violencia, en una de las cuales John intentó estrangularla (Ellmann, 1959/1991, p. 59; Joyce, S., 1960, p. 61).

James Joyce es el segundo hijo de este matrimonio y vino a sustituir al deseado primogénito muerto dos semanas después de nacer, en 1881, del cual su padre dijo "Mi vida quedó enterrada con él" (Gorman, 1945, p. 11; Ellmann, 1959/1991, p. 37; 839, n. 48). Muerto el primero, unos meses después ya esperaban al segundo, James, que nacería el 2 de febrero de 1882. James era el nombre de su bisabuelo, un acaudalado propietario de Cork, nacionalista y anticlerical que fue incluso condenado a muerte sin que se cumpliera la sentencia (Ellmann, 1959/1991, p. 28; Joyce, J., 1995, p. 42). Este primer James Joyce inauguró una suerte de tradición familiar al llamar a su único hijo James Augustine Joyce, abuelo del escritor. Este segundo James tuvo a su vez un único hijo, el padre de Joyce, y quiso llamarlo también James, pero la tradición se vio truncada por el azar de la intervención de un empleado borracho que en vez de "James" escribió "John" (Gorman, 1945, p. 12). La transmisión del mismo nombre para el hijo único es coartada ya en la generación del padre del escritor, quien intenta no obstante restituir la 


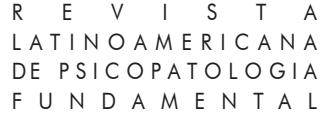

tradición al nombrar a su segundo hijo. La muerte del primogénito de John le deja a James la elección forzada de romper con tres generaciones de hijos únicos (Gorman, 1945, p. 13; Joyce, S., 1960, p. 46). Nuevamente por un error no pueden inscribirlo en la tradición familiar, que le destinaba la composición de nombres de su bisabuelo y de su abuelo (James Augustine Joyce) y queda nombrado como James Augusta Joyce (Gorman, 1945, p. 11; Ellmann, 1959, p. 37).

Durante el embarazo de James, su padre hipotecó una primera propiedad y en los meses que siguieron al nacimiento, hipotecó tres propiedades más. El nacimiento de James Joyce se acompaña entonces de una hipoteca que inicia la sangría de propiedades que habría de llevar a su familia a la ruina y del fallido intento de inscribirlo en una tradición. El padre de Joyce "llenó la casa de hijos y de deudas" (Ellmann, 1959/1991, p. 37), se aplicó con idéntica diligencia a engendrar hijos y a acumular hipotecas sobre sus propiedades heredadas. En el lapso de 10 años este matrimonio tuvo cuatro hijos y seis niñas, sin contar los hijos que no sobrevivieron. May estuvo embarazada 15 veces. En la biografía de Gorman (1945), revisada y autorizada por Joyce, consta sin embargo que fueron 16 o 17 los hijos que nacieron en el transcurso de 18 años y que 5 de ellos murieron en la infancia y/o la adolescencia. Hipotecaron 11 propiedades hasta quedarse sin ninguna (Ellmann, 1959/1991, p. 37).

Desde pequeño, Joyce se convirtió en una suerte de promesa que su padre alimentaba con la esperanza de que los salvara de la miseria (Joyce, S., 1960, p. 30). Era la figura central para su padre, el único privilegiado entre todos los hermanos (Gorman, 1945, p. 16). Su infancia y adolescencia están atravesadas por las sucesivas mudanzas (Gorman, 1945, p. 25), y por el espectáculo de un padre que se preocupaba por salvar el escudo familiar de los acreedores mientras que dilapidaba su fortuna (Joyce, S., 1960, p. 147). Joyce lo definió directamente como "un hombre quebrado" (Ellmann, 1959/1991, p. 38), una suerte de padre de pacotilla (p. 37). El hermano de James Joyce, Stanislaus, decía que su padre pertenecía a esa clase de hombres que no pueden ser miembros activos de ningún sistema social porque son saboteadores de la vida (Joyce, S., 1960, p. 54).

El padre de Joyce nunca se interesó por el gusto literario de su hijo ni por sus producciones, era más bien un aficionado al deporte, la música, la política y la bebida, llegó incluso a decirle a su hijo con respecto a sus libros: "Como es incapaz de contar esa anécdota como yo, debe conformarse con eso" (Ellmann, 1959/1991, p. 40). Era tal su rechazo hacia el saber de los libros que consideraba a la lectura excesiva como un signo de debilidad mental (Gorman, 1945, p. 21). 


\section{LITERATURA, PSICOPATOLOGIA}

\section{Posición fundacional y efectos del rechazo}

Este retrato de la dimisión paterna nos da la pauta de con qué se encontró Joyce, cuáles fueron las condiciones de lo que se le ofreció. Lacan (19681969/2006) señala la importancia de lo que llama "biografía original" proponiendo no reducirla al anecdotario de la historia personal, sino que allí puede leerse la forma en que se le presentaron al sujeto los deseos del padre y de la madre, lo que le fue ofrecido del saber, el goce y el objeto $a$. Es en la manera en que le fueron presentados cada uno de estos términos al sujeto, en esa oferta fundamental, que radica lo que se llama "impropiamente" la elección entre psicosis y neurosis: "No hubo elección, puesto que la elección ya estaba hecha a nivel de lo que se le ha presentado al sujeto" (p. 332). ¿Qué se le ofreció? Convertirse en el sustituto del deseado primogénito muerto ${ }^{2}$ de este matrimonio que sólo se entendía musicalmente. Salvar a la familia de la ruina, cuyo puntapié inicial fue la hipoteca que acompaña a su nacimiento. James contaba como sustituto de un muerto y como potencial salvador. El talento de Joyce valía para el padre en tanto promesa de salvación de aquellas obligaciones que le competían a él mismo como padre de una familia que no dejó de crecer aun ante la miseria económica. Se delinea entonces la figura de lo que Lacan (1958/1966b) ha llamado "impostura paterna" y que en 1975 califica como Verwerfung de hecho y dimisión paterna para el caso de Joyce.

Este rechazo de la impostura paterna, que define a la posición psicótica para Lacan (1958/1966b), puede leerse por sus efectos a nivel de la estructuración de la realidad y del cuerpo, y por una peculiar relación al lenguaje y al lazo social. A nivel descriptivo, todos los biógrafos coinciden en señalar la devoción de Joyce por su padre dado que, a diferencia de su hermano Stanislaus, él no lo criticaba ni lo aborrecía sino que lo acompañaba. Ahora bien, la operación de la Verwerfung no se deduce del retrato del padre imaginario sino de los efectos del rechazo de esta referencia común en la relación con el cuerpo y el lenguaje. En términos de Lacan (1975/2005b), podríamos definir los efectos de la Verwerfung en la relación con el cuerpo como la posibilidad de dejarlo caer, con respecto al lenguaje como una relación a la

\footnotetext{
2 Joyce no desconocía esto, en el Portrait fantasea con su muerte y recuerda al hermano muerto: "Que me entierren en el viejo cementerio junto a mi hermano mayor" (Joyce, J., 1916/1995, p. 26).
} 


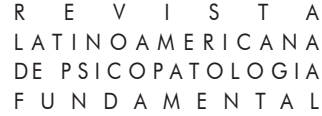

palabra que resulta impuesta. Pasaremos ahora a situar los efectos de la Verwerfung con respecto al lenguaje.

\section{Posición en el lenguaje: el pathos de las palabras impuestas}

El 17 de febrero de 1976 Lacan comenta un caso de una presentación de enfermos cuya particularidad eran ciertas palabras que le resultaban impuestas al paciente, quien decía sufrir de telepatía. A propósito del caso, Lacan se pregunta cómo es posible que los hombres normales no sientan que las palabras de las que dependen les son impuestas, que son una suerte de parásitos, una forma de cáncer que aflige al ser humano. Aquí Lacan se remite a Joyce y a su hija Lucía, diagnosticada como esquizofrénica y que Joyce defendía diciendo que ella era una telépata (Lacan, 1975-1976/2005a, p. 95-96). Para Lacan, Joyce le atribuye a su hija algo que es la prolongación de su propio síntoma: las palabras impuestas. Por momentos es difícil decidir si Joyce intentaba liberarse del parásito de la palabra o más bien se dejaba invadir por sus propiedades fonemáticas (p. 97). Algunos tramos de la obra parecen decantarse en un sentido y otros en el contrario. Veamos ahora de qué forma lo experimentaba.

Desde muy pequeño Joyce era diferente de los otros niños, él no quería jugar, permanecía más bien como un observador indiferente pero ultra atento del espectáculo del mundo y archivaba con paciencia cuanto veía, manteniéndose apartado de los demás (Gorman, 1945, p. 27; Joyce, J., 1916/1995, p. 71, 74, 77). Cada evento y cada personaje le afectaban íntimamente, herían su sensibilidad, como si careciera de protección ante lo que venía del exterior, primaban su instinto observador y su carácter sensitivo e introspectivo (Gorman, 1945, p. 45-46). Su hermano decía que nada se le escapaba y que James mismo le había dicho que no veía las cosas, sino que las absorbía (Joyce, S., 1960, p. 145). Su lúcida y fría indiferencia, su inflexible dureza y sinceridad nunca lo abandonaban y le daban un aire de estar a la defensiva (p. 96, 171, 178) o incluso de una arrogancia que parecía erigir una "pared invisible" entre él y sus compañeros (Gorman, 1945, p. 51). Esa actitud distante, sumada a su intolerancia con las falsedades de las relaciones sociales, llegaba incluso a despertar la hostilidad en los otros (Joyce, S., 1960, p. 209).

Su percepción de la realidad era altamente sonora, veía el murmullo de las cosas y tenía una sensibilidad excesiva para las palabras (Joyce, S., 1960, p. 209). Cuando caminaba largas horas por la calle, su ánimo investigador lo 


\section{LITERATURA, PSICOPATOLOGIA}

mantenía completamente atento a cualquier pequeño fragmento de conversación trivial que escuchara al pasar y que le producía "una impresión suficientemente aguda para herir dolorosamente su sensibilidad" (p. 227-228). Se trataba de partes de conversaciones ordinarias que adquirían para Joyce el carácter de "epifanías". En Stephen Hero las define así: "una súbita manifestación espiritual, ya fuere en la vulgaridad de la alocución o del gesto, ya fuere en una faz memorable del mismo espíritu" (p. 228). Momentos delicados y evanescentes que debía registrar y al parecer, hasta provocar. Da el ejemplo del reloj de una oficina pública de Dublín, que es capaz de producir una epifanía: "Su alma, su qué, salta a nosotros desde la vestidura de su apariencia. El alma del objeto más común, cuya estructura está tan bien ajustada, nos parece radiante. El objeto cumple su epifanía" (p. 230).

La epifanía correspondía entonces a la irradiación de los objetos, a un modo de presencia positiva de los mismos. Joyce recibía entonces en la percepción el alma de las cosas más allá de sus apariencias, se le imponía algo del ser de los objetos. Muchos son los pasajes de su obra en que Joyce testimonia el haber sentido "presencias", a modo de fuerzas ocultas que incluso actúan sobre él, presencias oscuras, sutiles, susurrantes: "Ondas sutiles penetraban todo su ser. Las manos se le crispaban convulsivamente y apretaba los dientes como si sufriera la agonía de aquella penetración. En la calle extendía los brazos para alcanzar la forma huidiza y frágil que se le escapaba incitándole..." (Joyce, J., 1916/1995, p. 110-111). La presencia de los objetos se impone y penetra sus sentidos.

En la biografía de su hermano, Stanislaus Joyce define a las epifanías como manifestaciones o revelaciones, "observaciones irónicas sobre deslices, pequeños errores y gestos, cosas baladíes mediante las cuales la gente traiciona las muchas cosas que es capaz de disimular" (Joyce, S., 1960, p. 149), una suerte de "expresión de su espíritu dolorido y de las impresiones indelebles que le hicieron los acontecimientos. Los sentimientos falsos eran para él un espantajo y le repugnaba traslucirlos" (p. 259). Eran observaciones de gran exactitud sobre temas y personas banales que revelaban la importancia del subconsciente. Entre ellas había también algunos sueños, de los cuales Joyce pensaba que eran una revelación de aquello que se encubría inconscientemente con pensamientos controlados (p. 152).

Para Lacan (1975-1976/2005a) estas epifanías se caracterizan por que el inconsciente se liga a lo real, debido al lapsus en el anudamiento que produjo un desprendimiento de lo imaginario (p. 154), de ahí que el ser del objeto se presente sin el velo de la apariencia. Por lo tanto Lacan lee la soltura del 


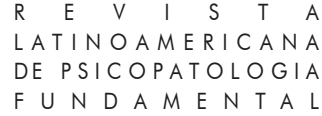

registro de lo imaginario no sólo en los fenómenos que afectan al cuerpo sino también en la peculiar relación a las palabras. Joyce tenía una percepción epifánica del mundo, atestada de presencias y sonoridades. Los sonidos, componentes más elementales del lenguaje, se imponen en su experiencia del mundo, atravesando su cuerpo como ondas que lo penetran. Joyce descompone estas presencias que lo impactan y hieren su sensibilidad y las registra en un cuaderno de epifanías.

Pero no se trataba únicamente de una sensibilidad acrecentada a los sonidos, en la obra aparecen varios testimonios de cómo convivía con los ecos de lo escuchado en una "orgía mental" que le costaba dominar, una suerte de "estupor imaginativo" (Joyce, J., 1916/1995, p. 124) y un "zumbido vacío de voces internas" en el que retornaba el llamado de sus profesores incitándolo a ser un buen católico, fuerte, viril y saludable, ser fiel a la patria, el llamado "a ayudar a vivificar su lenguaje y sus tradiciones", mientras "otra voz lo invitaría a reconstruir con su trabajo la derruida hacienda de su padre" (p. 92-93). Voces que su primer biógrafo, Gorman (1945), confirma llamándolas primero "voces de censura" (p. 53), "lucha mental" (p. 54) y luego directamente "voces misteriosas" (p. 60). Voces que Aubert (2005) entiende como

392 "efectos de voces del significante" con los cuales Joyce fabrica un saber-hacer ligado a un arte de la voz, a una práctica fonatoria del significante.

Su carácter de ajenidad y extrañeza está dado por la posición que James toma antes esas voces: "Sólo les prestaba atención por algún tiempo, y era feliz cuando podía estar lejos de ellas, fuera del alcance de su llamamiento, solo, o en compañía de sus propios y fantasmales compañeros" (Joyce, J., 1916/1995, p. 92-93). Esta experiencia de voces internas podía llegar incluso a transformarse en "un zumbido de palabras incoherentes" que afectaba "la línea constructiva de sus pensamientos" (p. 181).

Un episodio de sus 12 años, corroborado por los biógrafos, permite mensurar esta relación con las palabras impuestas como efecto de la operatoria de la Verwerfung. La coyuntura es un viaje a Cork- tierra de sus abuelosen el que acompaña a su padre para subastar las últimas propiedades que poseían. El padre insiste en contar anécdotas de sus amigos de juventud, pero Joyce no deja de pensar en que van a "perder lo propio" (p. 96). Podría hipotetizarse que entonces adquiere fuerza el llamado paterno que pesa sobre James en tanto "mesías material" que habría de salvar a la familia de la ruina (Joyce, J., 1960, p. 240). Ya en el viaje tiene la sensación de que los otros pasajeros pueden hacerle daño, aparecen palabras sin sentido que intenta acomodar al ritmo del tren. Esta "música" compuesta por esas palabras, el 


\section{LITERATURA, PSICOPATOLOGIA}

traqueteo del tren y los postes de telégrafo que se sucedían cada 4 segundos lo aliviaron (Joyce, J., 1916/1995, p. 96-97).

El padre lo lleva al colegio al que asistió cuando estudiaba medicina para mostrarle cómo dejó su huella en los pupitres, quiere que su hijo vea sus iniciales grabadas en el anfiteatro de anatomía - iniciales que comparte con el hijo (Aubert, 2005). Gorman (1945) nos aporta que el padre estudió allí tres años infructuosamente aunque decía que había obtenido varios diplomas, no obstante sólo quedaron sus iniciales grabadas en la madera porque los diplomas "desaparecieron" ( p. 13). El padre explicaba su ausencia de diplomas adjudicándosela a un prestamista a quien había empeñado una maleta "En la maleta tenía una dentadura postiza y mis diplomas pero el prestamista vendió todo: ¡maleta, dentadura y diplomas!” (Gorman, 1945, p. 13; Ellmann, 1959/1991, p. 30). El tono de la anécdota resulta indicativo de la impostura en la enunciación del padre. Ante el pedido de éste de reconocer las iniciales del nombre del padre grabadas, James Joyce ve en cambio la palabra "Feto" en latín, la palabra se impone y se repite, al punto de quedar tomado por esa visión, necesitando irse para escapar de ella: "Esta palabra sobrecogió su espíritu; le pareció sentir en torno a él a los ausentes estudiantes del colegio y espantarse de su compañía. Y una visión de la vida de ellos que las palabras de su padre habían sido incapaces de evocar, se elevó ante sus ojos como si brotara de las letras grabadas en la mesa (...) la palabra y la visión retozaban delante de sus ojos al regresar por el patio camino de la puerta de entrada. Le extrañaba el encontrar en el mundo externo huellas de aquello que él había estimado hasta entonces como una repugnante y peculiar enfermedad de su propia imaginación" (Joyce, J., 1916/1995, p. 99).

Esta enfermedad, este pathos de la palabra se le impone al punto de sentir que es observado por ella: "Aquellas letras grabadas en la manchada madera del pupitre le estaban contemplando fijamente" (p. 100-101). Queda confundido después del episodio, preguntándose acerca de los límites de lo real y de su imaginación: "No había cosa del mundo real que le dijera nada, que lo conmoviera, a no ser que despertara un eco de aquellos alaridos furiosos que él sentía brotar de su interior. (...) Apenas si podía reconocer como propios sus pensamientos" (p. 102). Logra restablecerse de este episodio repitiendo su nombre, el de su padre, el de la ciudad en la que están, sólo podía recordar los nombres. Algo del significante se le impone en su materialidad misma, por fuera del sentido, allí donde el padre invoca las coordenadas de su impostura. Algo de su relación a la palabra le resulta impuesto y por momentos él parece más bien dejarse invadir por la sonoridad del mundo. 


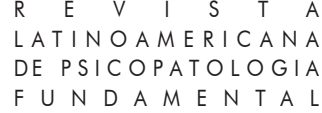

Pero Joyce no queda impávido frente a la experiencia del parásito lenguajero, comienza a acopiar esas palabras, el fulgor del ser de las cosas que lo acicatea en su visión epifánica de la vida. Queda hipnotizado por las conversaciones más vulgares, que somete al registro primero y luego a la permutación y combinación letra por letra (Joyce, J., 1960, p. 39). El trabajo de las epifanías ha comenzado y se acumula en cuadernos que luego se convertirán en insumos de sus obras mayores (Baños Orellana, 1998; Millot, 1987). Reconoce que su experiencia no es la del común de los mortales: "La gente se le aparecía extrañamente ignorante del valor de las palabras que empleaba con tanta volubilidad. Y poco a poco, a medida que esta indignidad vital se imponía a él, se fue enamorando de una tradición idealizadora, más auténticamente humana. Este fenómeno se le antojó grave y comenzó a ver que la gente se coaligaba en una conspiración de sordidez (...) No deseaba tal reducción para sí mismo" (Joyce, J., 1960, p. 32-33). James se interna entonces en una adoración meticulosa de las palabras más banales, comienza a armar un tesoro de frases con las que construirá su enigma de una manera hasta entonces desconocida por los cánones de la literatura, marcando un antes y un después con su obra. La musicalidad de las palabras gana por sobre

394 el sentido y la proliferación de significados, que Joyce deja caer para privilegiar los acordes de esa experiencia éxtima del parásito lenguajero.

\section{Conclusión}

Lacan sostiene que el valor de la obra de Joyce es que da la esencia del síntoma, su abstracción, su aparato (1975/2005b, p. 165). Lo que transforma a Joyce en "el síntoma" es justamente ese síntoma puro de la relación al lenguaje que aparece como experiencia de una palabra parásita y a la vez sumamente erotizada, una palabra que se goza por fuera del sentido, en un uso fonético que hace del síntoma un acontecimiento del cuerpo (Lacan, 1979/2001b). Joyce lleva al síntoma a la potencia del lenguaje (Lacan, 1975/2005b), lo encarna en su particular experiencia del mundo. Estas palabras y sonoridades impuestas que vienen de lo real pueden ser luego descompuestas y transliteradas en un trabajo que dará origen al material de su obra mayor. El caso Joyce ilumina así una experiencia de lo real desprendida de lo imaginario y del sentido, aunque no por eso incompatible con la genialidad de la creación. 


\section{LITERATURA, PSICOPATOLOGIA}

\section{Referencias}

Aubert, J. (2005). Exposé au séminaire de Jacques Lacan. In J. Lacan. Le séminaire. Livre XXIII. Le sinthome (pp. 171-188). Paris: Seuil. (Trabajo original publicado en 1976).

Baños Orellana, J. (1998, junio). Primeros apuntes acerca de las epifanías joyceanas. El caldero de la Escuela, Buenos Aires, 60, 70-79.

Ellmann, R. (1991). James Joyce. Barcelona: Anagrama. (Trabajo original publicado en 1959).

Freud, S. (1979). Intervención en el acta del 11 de diciembre de 1907. In H. Nunberg, \& E. Federn (Comp.). Las reuniones de los miércoles. Actas de la Sociedad Psicoanalitica de Viena (Tomo I, pp. 269-278). Buenos Aires: Nueva Visión. (Trabajo original publicado en1906-1908).

Freud, S. (1994). Dostoievski y el parricidio. In Obras completas (Tomo XXI, pp. 171-191). Buenos Aires: Amorrortu. (Trabajo original publicado en 1928).

Freud, S. (1999a). El delirio y los sueños en la Gradiva de W. Jensen. In Obras completas (Tomo IX, pp. 1-80). Buenos Aires: Amorrortu. (Trabajo original publicado en 1907).

Freud, S. (1999b). Un recuerdo infantil de Leonardo da Vinci. In Obras completas (Tomo X, pp. 53-127). Buenos Aires: Amorrortu. (Trabajo original publicado en 1910).

Gorman, H. (1945). James Joyce (El hombre que escribió “Ulises”). Buenos Aires: Santiago Rueda. (Trabajo original publicado en 1941).

Joyce, J. (1960). Esteban el héroe. Buenos Aires: Sur editorial.

Joyce, J. (1995). Retrato del artista adolescente. Madrid: Alianza Editorial. (Trabajo original publicado en 1916).

Joyce, S. (1960). Mi hermano James Joyce. Buenos Aires: Compañía Fabril Editora.

Julien, P. (2001). Du symptôme au sinthome: la psychose lacanienne. La clinique lacanienne, 1(5), 63-67.

Kong, P. (2011). Psychose: réaménagements de la suppléance perverse en Joyce, Wittgenstein et quelques autres... Revue Figures de la Psychanalyse, 21(1), 129-139.

Lacan, J. (1966a). Jeunesse de Gide ou la lettre et le désir. In Écrits (pp. 739-764). Paris: Seuil. (Trabajo original publicado en 1958).

Lacan, J. (1966b). D’une question préliminaire à tout traitement possible de la psychose. In Écrits (pp. 531-583). Paris: Seuil. (Trabajo original publicado en 1958).

Lacan, J. (2001a). Hommage fait à Marguerite Duras, du ravissement de Lol. V. Stein. In Autres écrits (pp. 191-198). Paris: Seuil. (Trabajo original publicado en 1965). 


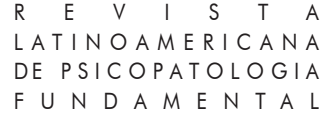

Lacan, J. (2001b). Joyce le symptôme. In Autres écrits (pp. 565-570). Paris: Seuil. (Trabajo original publicado en 1979).

Lacan, J. (2005a). Le séminaire. Livre XXIII. Le sinthome. París: Seuil (Trabajo original publicado en 1975-1976).

Lacan, J. (2005b). Joyce le symptôme. In Le séminaire. Livre XXIII. Le sinthome (pp. 161-169). Paris: Seuil. (Trabajo original publicado en 1975).

Lacan, J. (2006). Le séminaire. Livre XVI. D'un Autre à l'autre. Paris: Seuil (Trabajo original publicado en 1968-1969).

Leite, S. (2016, junio). Habitar, construir, existir: algunas consideraciones sobre el cuerpo en las psicosis. Revista Latinoamericana de Psicopatología Fundamental, Sao Paulo, 19(2), 214-224.

Miller, J.-A. (1990). Acerca del Gide de Lacan. Buenos Aires: Malentendido.

Miller, J.-A. (2007). La invención psicótica. Virtualia, VI(16). Descargado de <www. virtualia.eol.org.ar>.

Millot, C. (1987). Épiphanies. In J. Aubert (Comp.). Joyce avec Lacan. Paris: Navarin.

Pommier, G. (1998). Louis du néant: la mélancolie d'Althusser. Paris: Aubier.

396 Redmond, J. D. (2014). Ordinary psychosis and the body: a contemporary lacanian approach. New York: Springer.

Rosa, M. (2009, marzo). A psicose ordinária e os fenómenos de corpo. Revista latinoamericana de psicopatología fundamental, Sao Paulo, 12(1), 116-129.

Soler, C. (2001). L'aventure littéraire ou la psychose inspirée. Roussseau, Joyce, Pessoa. Paris: Éd. du Champ lacanien.

Spencer, T. (1960). Introducción. In J. Joyce, Esteban el héroe (pp. 13-26). Buenos Aires: Sur.

Svolos, T. (2009). Ordinary psychosis. The symptom 10. Descargado de $<$ www.lacan. com>.

\section{Resumos}

(O jovem Joyce e o pathos da linguagem )

Este artigo fornece uma construção do caso de James Joyce como um caso clínico, fazendo uma revisão das diretrizes que Lacan enfatizou em 1975-1976. Metodologicamente é baseado na obra autobiográfica sobre a infância e adolescência e oferece uma leitura da constelação de nascimento original, a posição 


\section{LITERATURA, PSICOPATOLOGIA}

fundamental da orientação subjetiva, os efeitos da rejeição e do pathos singular que o afligia: as palavras imposta ou a experiência da linguagem parasita.

Palavras-chave: psicanálise, psicose, literatura, sintoma

(The young Joyce and the pathos of language)

This article provides a construction of the case of James Joyce as a clinical case by making a review of the guidelines that Lacan emphasized in 1975-1976. Methodologically it's based on the autobiographical work about childhood and adolescence and offers a reading of the original constellation of birth, the foundational position of the subjective orientation, the effects of rejection and the singular pathos that afflicted him: the words imposed or experience of parasite language.

Key words: Psychoanalysis, psychosis, literature, symptom

(Le jeune Joyce et le pathos du langage )

Cet article fournit une construction du cas de James Joyce comme un cas clinique à partir des lignes directrices que Lacan soulignait en 1975-1976. Méthodologiquement il est basé sur le travail autobiographique sur l'enfance et l'adolescence de James Joyce et offre une lecture de la constellation d'origine de sa naissance, la position fondamentale de l'orientation subjective, les effets du rejet et le pathos singulier qui l'affligeaient: les mots imposés ou la l'expérience du langage parasite.

Mots clés: Psychanalyse, psychoses, littérature, symptôme

(Der junge Joyce und Pathos Sprache)

Dieser Artikel enthält eine Konstruktion des Koffers von James Joyce als klinischer Fall durch eine Überprüfung der Richtlinien machen, die Lacan 1975/1976 betont. Methodisch basiert es auf dem autobiografisch Arbeit über Kindheit und Jugend und bietet eine Lesung des ursprünglichen Konstellation der Geburt, die grundlegende Position der subjektiven Orientierung, die Auswirkungen der Ablehnung und der singuläre Pathos, das ihn betroffen: die Worte auferlegt oder Erfahrung der Parasit Sprache.

Palavras-chave: Psychoanalyse, psychose, literatur, symptom

\section{(年輕的喬伊斯和悲愴的語言)}

本文提供了詹姆斯·乔伊斯的情况下, 作为一个临床病例通过的拉康在 1975-1976强调准则审核的建设。从方法论它是基于对儿童和青少年的自传体 作品, 并享有熥生的原始星座的读数, 主观导向的基础性地位, 排斥反应的影 响, 并折磨他奇异的悲怆：字强加或寄生虫的语言经验。

心理分析 - 精神病 - 文學 -症狀 


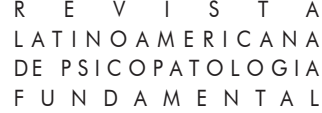

Citação/Citation: Battista, J. (2017, junho). El joven Joyce y el pathos del lenguaje. Revista Latinoamericana de Psicopatologia Fundamental, 20(2), 382-398. http://dx.doi.org/10.1590/ 1415-4714.2017v20n2p382.11

\section{Editores do artigo/Editors: Vários}

Recebido/Received: 20.2.2017/ 2.20.2017 Aceito/Accepted: 19.04.2017 / 4.19.2017

Copyright: (C) 2009 Associação Universitária de Pesquisa em Psicopatologia Fundamental/ University Association for Research in Fundamental Psychopathology. Este é um artigo de livre acesso, que permite uso irrestrito, distribuição e reprodução em qualquer meio, desde que o autor e a fonte sejam citados / This is an open-access article, which permits unrestricted use, distribution, and reproduction in any medium, provided the original authors and sources are credited.

Financiamento/Funding: Pesquisa financiada pelo Consejo de Investigaciones Científicas y Técnicas (CONICET) / The research was funded by the Consejo de Investigaciones Científicas y Técnicas (CONICET).

Conflito de interesses/Conflict of interest: A autora declara que não há conflito de interesses / The author has no conflict of interest to declare.

\section{Julieta De Battista}

Docteur en Psychopathologie de l'Université de Toulouse (Tolouse, França); Especialista en Clínica Psicoanalítica de la Universidad Nacional de La Plata (La Plata, Argentina); Investigadora Adjunta Asociada de la Comisión de Investigaciones Científicas de la Provincia de Buenos Aires (CIC-UNLP) (Buenos Aires, Argentina); Becaria Post-doctoral del Consejo de Investigaciones Científicas y Técnicas (CONICET); Profesora a cargo de la Cátedra de Psicopatología I de la Universidad Nacional de La Plata. Profesora invitada de la Maestría en Psicoanálisis de la Universidad de Buenos Aires (UBA) (Buenos Aires, Argentina).

Facultad de Psicología

Calle 51 entre 123 y 124 - Ensenada

CP 1925. La Plata, Provincia de Buenos Aires, Argentina.

julietadebattista@gmail.com

This is an open-access article, which permits unrestricted use, distribution,

(cc) BY-NC and reproduction in any medium for non-commercial purposes provided the original authors and sources are credited. 